\title{
A Board-Game for Co-Designing Smart Nature Environments in Workshops with Children ${ }^{\star}$
}

\author{
Rosella Gennari ${ }^{10000-0003-0063-0996]}$, Maristella Matera 2[0000-0003-0552-8624], \\ and Alessandra Melonio ${ }^{1[0000-0001-6655-1946]}$ Eftychia \\ Roumelioti ${ }^{1[0000-0003-3293-4521]}$ \\ 1 Free University of Bozen-Bolzano, Piazza Domenicani 3, 39100 Bolzano, IT \\ 2 Politecnico di Milano, Piazza Leonardo da Vinci 32, 20133, Milano, IT
}

\begin{abstract}
In recent years, the Human Computer Interaction community has increasingly engaged children in the design process of technology for them as co-designers, and recently as protagonists in co-design. It has also recognised the need of "bringing children back to nature". This paper combines both lines of research, giving children the role of protagonist co-designers of smart nature ecosystems. In order to engage children as co-designers, the research reported in this paper has employed a playful solution: a board game for children for co-designing smart interactive objects for outdoors nature ecosystems. This paper illustrates the genesis and recent evolution of the board-game in two workshops with children of different ages and gender. Its conclusions draw lessons for involving children as protagonist co-designers of smart nature ecosystems.
\end{abstract}

Keywords: Smart nature $\cdot$ children $\cdot$ co-design $\cdot$ cultures of participation and meta-design approaches.

\section{Introduction}

Research indicates that time spent outdoors in nature is important for children's development, but children spend much less time outdoors today than in the past. Technology is considered to be one of the main causes of children's living indoors [6]. Some researchers believe that technology can also be used to bring children outdoors, in novel smart nature environments, that is, nature environments augmented with "smart" behaviours, e.g., [24]. Along this line of research, recent initiatives tried to make children the protagonists of the ideation of novel smart nature environments for them; e.g., researchers have organised co-design workshops with paper-based generative toolkits in order to engage children in the design of smart objects for spending time outdoors in nature [22]. This paper also addresses the issue of how to make children the protagonists of the design of novel smart nature environments for them. In order to do so, this paper introduce a card-based board game for ideating smart nature environments with children through play, in which the children have the role of protagonists.

* Members from the first institution were supported by the GeKI project. 
The paper starts by reviewing the relevant literature for co-designing with children for nature. Then it describes the latest version of the board game and what originated it. It continues with the two workshops in which the game board was used by two 4-member groups of 11 and 14 years old children, 4 males and 4 females. The game-play gave a rich set of data, qualitative and quantitative, which are reflected over in the paper conclusions.

\section{Related Work and Background}

Co-design protagonists. In the early days of Human Computer Interaction (HCI), children were involved as users or testers of technology for them. Subsequently, following a Participatory Design (PD) tradition, children started to be involved as co-designers in different stages of design, whether as design informants or full partners, e.g., $[11,14]$. Recently, a complementary perspective on children as codesigners has emerged. This perspective adds what motivates or gives children benefits in co-design, considering them the protagonists of design [21]. In this view, children guide the design process and are given the means to critically reflect on technology and its role in their lives. In this paper, we aim at engaging children as co-design protagonists.

Generative toolkits. Numerous generative toolkits are used to engage people and enable them to co-design, e.g., visual materials (e.g., photos), storytelling kits. Recent workshops have employed cards to both engage people and ideate smart solutions with them $[5,23,33]$. The systematic analysis in [30] lists different benefits of card-based design, such as to foster creative thinking and problem solving (e.g., [17, 28]), support the design of a product or service considering users' needs (e.g., [4]), provide methods or information for specific domains (e.g., [8]), facilitate collaborative working in participatory and co-design sessions (e.g., [18]). Sets or decks of cards, such as the IoT Card Set [2], the IoT Design Deck [10] and the Tiles Cards [27], have been used for co-designing or augmenting every-day's objects with smart behaviours. Adapted versions of Tiles Cards were employed in co-design workshops with children as well $[13,26]$.

However, the most useful cards (i.e., likely to lead to design outcomes) consider the environment's specificity, e.g., cards for co-designing smart cities should be different than cards for designing toys [19,30]. Moreover, rules for the usage of cards should support the purpose of the cards [25,30]. Cards and rules should be designed for their intended users, e.g., by considering children's characteristics [19]. In particular, rules for using cards with children can be conveyed as a game's rules; playfulness is widely recognised fundamental for engaging children, and triggering creativity, e.g., [28]. These are ideas also pursued in this paper.

From Smart Cities to Smart Nature. There are a number of workshops meant for co-designing smart cities with adults, some using cards or games. For instance, Tiles cards have been used in smart city workshops with different stakeholders [16]. There are less smart city initiatives with children, which use cards or 
games. LocaLudo, for example, is a board platform that involves families in the design of new architecture landscapes through playing [20].

Recently, HCI research is voicing the need to facilitate children's engagement in the design of smart natural environments, e.g., [3]. In this context, children have been involved as informants or users. For instance, contextual inquiries with children led to the emergence of the ABBOT smart toy to engage children in natural outdoors environments [7]. To the best of our knowledge, however, there are few workshops for co-designing smart nature environments with children. One of the few exceptions is the project by Smart Toy LLC, which engaged children in co-design sessions of a new app and smart toy that encourages them to empathise with nature [22].

The goal of our research is also to continue this line of investigation and co-design smart nature ecosystems with children through a board game with cards for nature environments. The origins of the game and its evolution are unravelled in the remainder of this paper.

\section{The SNaP Board-Game}

The Smart Nature Protagonists (SNaP) board-game is a cooperative game for co-design workshops, with ideas taken from traditional board-game design [31]. It considers children as co-designers in the design practice of augmenting outdoor environment objects with the use of tools and rules explained in the following.

\subsection{Tools and Setup}

The game is designed for 2-4 players, in the role of Designers, and a moderator, in the role of a city Mayor. It takes place in the central park of a city the Mayor administers, and Designers work for. Each player should design a smart



Fig. 1. Scaffolding Map 
interactive object, and fulfill the missions given by the Mayor. It consists of: 1 Scaffolding Map (see Fig. 1), 1 Game Board (see Fig. 2), 4 Mission Cards, 4 Tokens, a deck of Nature Cards (see Fig. 3), 1 Table with all the available cards (see Fig. 3), Coins, 1 Dice, 4 Note Sheets (see Fig. 4) and 1 one-minute Hourglass. Each Designer takes a note sheet and a token. The Mayor keeps a copy of the cards of each category and the coins. The rest of the cards are placed shuffled and faced down on the game board at the corresponding category spot.

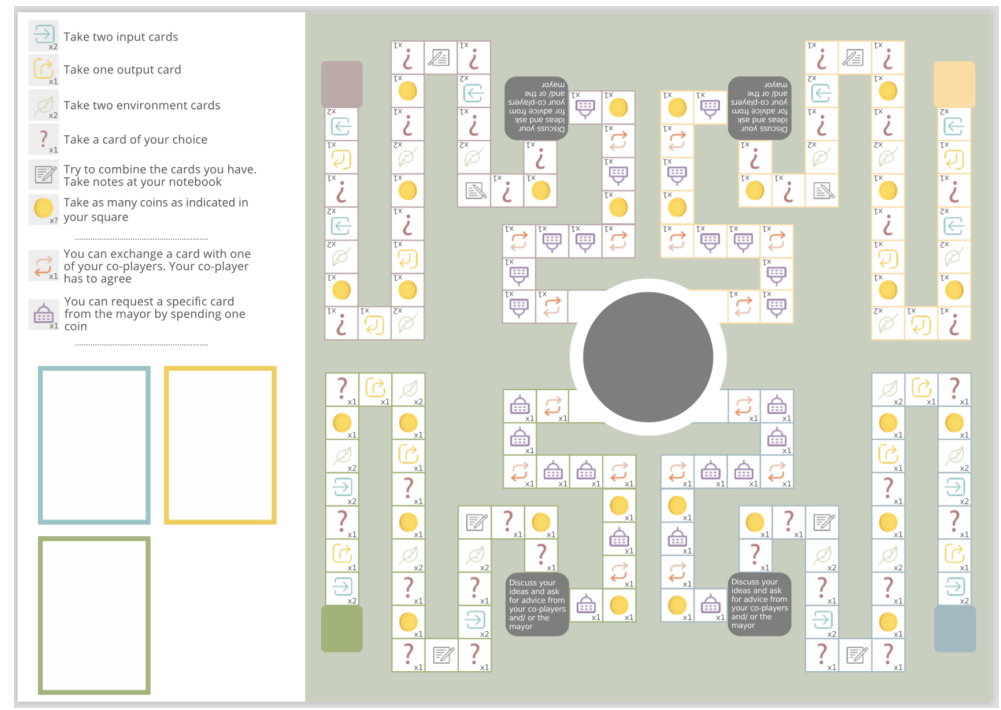

Fig. 2. Game Board

\subsection{Nature Cards}

Nature Cards (see Fig. 3) have been created to inspire ideas for making outdoor nature environments smart. With Nature Cards, we aim to make the design of smart interactive objects for outdoor nature environments accessible to children, so as to engage them as protagonists in the design process. The layout of the cards is based on the Tiles Ideation Toolkit [27], a card-based design toolkit for IoT user experiences. The original Tiles toolkit is meant to be generic with no focus on a specific context or for specific card users [15]. In our work, we focus instead on outdoor natural environments, and children, older than 8 years, as main users of cards. Therefore, our Nature Cards are especially designed for outdoors, and to be used by children aged from 8 years old onward. For instance, easy-to-recognise icons and a suitable language have been used to make them comprehensible and easy to perceive by the targeted age.

For creating Nature Cards, we run contextual inquiries into parks and nature environments. Afterwards, we selected for cards a series of outdoor objects, 
inputs and outputs which children can ideate and prototype with. Currently, Nature Cards are composed of three categories:

1. Environment Cards (18): they are green cards representing artifacts (e.g., a bench) or natural elements (e.g., a tree) that can be usually found in a park or any other outdoor nature environment;

2. Input Cards (20): they are blue cards representing sensors (e.g., motion sensor) and other input physical components (e.g, buttons) that trigger an interaction;

3. Output Cards (5): they are yellow cards representing actuators (e.g., sound) or other output physical components that react to the interaction.

Figure 3 shows the entire Nature Card deck.



Fig. 3. Nature Cards: top green cards are Environment Cards; middle blue cards are Input Cards; bottom yellow cards are Output Cards.

\subsection{Rules and Game-Play}

The game is supported by a narrative: the Mayor wants to organise a festival in the city's central park and needs Designers. Designers should carry out one of the following missions, and ideate smart interactive objects for the park:

1. Add playful and interactive attractions to the park; 
2. Help visitors explore hidden spots of the park;

3. Make sure the visitors respect the park during and after the festival;

4. Make sure the park is accessible to everybody.

Players can choose a specific mission from start or during the game play. In the former case, each player should have a different mission. In the latter case, missions have an inspirational and non-restrictive role. Players place their tokens at different colored square (see Fig. 2) and play to reach the central grey circle.

First step: cards are collected. Each player, in turn, throws the dice and moves the token the number of squares indicated by the dice. Depending on the square the token reaches, the player may be entitled to get one or more cards from the decks of cards, get coins, try to combine the cards and take notes, exchange or buy a card. Each time a player's token lands on the notebook space, the Mayor turns the hourglass and all the players individually should start reflecting on how to combine the cards they already have and use their Note Sheets.

Each Note Sheet consists of colorful spots to organise the cards players have, write down the cards they need, take notes and place their coins (see Fig. 2). Players place the cards they do not need on the corresponding place on their Note Sheet, as an indication that they are willing to exchange them. They can also refer to the all-cards Table to note down the extra cards they may need. The Note Sheet and the all-cards Table can also be used individually at any time during the game. Some cards are blank: if a player receives a blank card, the player can use it as any other card of his or her choice from the same category.

Middle step: ideas are discussed. When a player lands on or passes over the grey square in the middle of the path, he or she has to stop there and wait until all the other players reach their own grey square. When all players have reached this point, they have to present their ideas in turn to the rest of the team and the Mayor. Each player should give their opinion to the one presenting, and advise this on how to improve ideas. In the end of each turn, the Mayor is entitled to deliver her or his final advice to the player. At the end of this, each player should have an idea and what cards the player may be still in need of.



Fig. 4. Note sheet 
Final step: ideas are finalised. After the end of the discussion part, the players keep on moving towards the central circle. When a player lands on the exchange icon, he/she can either exchange or buy a card from another player. When the player lands on the city-hall icon, he or she can buy a card from the Mayor. Each card costs 1 coin. When all the players reach the center, they should present their final smart interactive objects with the corresponding cards to the Mayor.

\section{Pilot Workshops}

\subsection{Workshops with Adults and Children}

Preliminary versions of the game incrementally evolved by playing it. We started with three pilot workshops: one with five adults, all experts of HCI; two workshops with 2 11-years old children and 2 adults with expertise in HCI. Thanks to these pilot workshops we reached a version of both the game board and the cards that we considered ready to be used in co-design workshops.

A subsequent co-design workshop was organised [12]. This involved four 10 to 13 years old girls, two of whom had no prior experience of co-design or making, and two HCI experts, one acting as Mayor and the other as observer. This workshop helped assess the game-play rules. It also helped identify issues, especially in the introduction phase in which cards were explained, as the Mayor should have taken care especially of participants without experience of co-design or making. The game-play rules and introduction phase were then reflected over.

\subsection{Workshop with University Students}

Before proceeding with new co-design workshops with children, we decided to conduct a workshop for evaluating the game-play rules with others knowledgeable of HCI. We also wanted to investigate to which extent the rules would enable participants to generate ideas. We enrolled Masters students of Politecnico di Milano: 3 males attending the Computer Engineering Masters; 1 female attending the Communication Design Master. Their age ranged from 21 to 23 years. They all had previous exposure to the design of smart objects as they had attended an Interaction Design course that had required them to design and prototype smart interactive objects. The pilot workshop took place in a quiet room of Politecnico.

The students played as Designers, one expert researcher acted as Mayor. After a short introduction by the Mayor, who explained the game goal and its rules, the play started. Players soon observed that the game was not very appropriate for their age. Nevertheless, they appeared very engaged to the Mayor, and willing to identify possible ways to improve the game experience. In the end, they generated three different ideas, which are reported in Table 1.

One player, with the mission "Add playful and interactive attractions to the park", was unable to generate any idea. The reason is that this player collected very few, redundant cards that did not enable the generation of any significant 
Table 1. Ideas generated during the pilot workshop with university students. Missions the ideas relate to are reported in italics; employed cards are in capital letters

\begin{tabular}{|l|l|}
\hline Players & Interactive objects \\
\hline 1st & $\begin{array}{l}\text { In order to guide visitors towards hidden areas, I would use STREET } \\
\text { SIGNS which, thanks to a MOTION SENSOR, detect when people pass } \\
\text { nearby and thus street signs become evident thanks to blinking LEDs. }\end{array}$ \\
\hline 2nd & $\begin{array}{l}\text { In order to make sure the visitors respect the park during and after the } \\
\text { festival, I would equip STREET SIGNS with LEDs that are switched on } \\
\text { when garbage is thrown on the ground. }\end{array}$ \\
\hline 3rd & $\begin{array}{l}\text { In order to make sure the park is accessible to anybody, I would install } \\
\text { a DISPLAY on STREET LIGHTS close to some barriers, e.g., stairs, to } \\
\text { indicate alternatives paths. }\end{array}$ \\
\hline 4th & \begin{tabular}{l} 
This player was not able to elaborate any idea. \\
\hline
\end{tabular}
\end{tabular}

idea. Others experienced similar issues, e.g., in terms of available Input Cards or Output Cards. For this reason, the game rules were purposely revised, by including more squares in the game board that would enable players to gain further cards or exchange cards with other players.

\section{Two Workshops with Children}

With the version of the game presented in this paper, we organised two main co-design workshops. These workshops explored the following research questions: (1) children's ideas generated by playing the game; (2) children's engagement with the game; (3) children's overall experience with the game.

The workshops involved males and females, of different ages: Workshop 1 involved pre-teens; Workshop 2 involved young teens. Details on them are in the following. Figure 5 shows game-play sessions from both workshops.
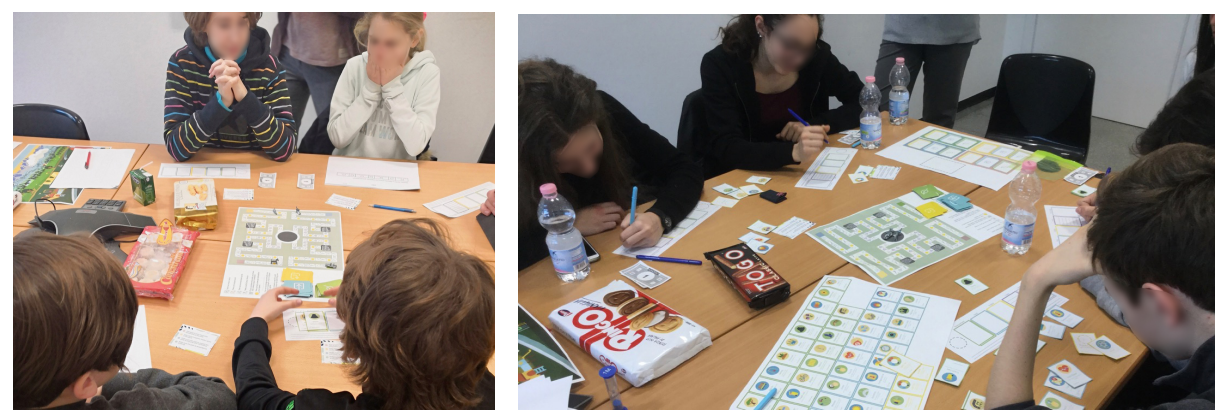

Fig. 5. Two game-play sessions from Workshops 1 and 2, respectively 


\subsection{Participants and Setting}

Eight kids, aged 11-14 years, participated in the workshops. The participants in Workshop 1 were 4 children, 2 females and 2 males, all aged 11 years old. The participants in Workshop 2 were 2 girls and 2 boys, all aged 14 years old. All children participated on a voluntary basis and their participation was asked to their parents through a consent form.

The workshops were run in a room of Politecnico di Milano; both lasted about 1.5 hours, also including the introduction parts (see the workshop format illustrated below). Children played the role of designers. In both workshops, the same two HCI experts were involved, one as Mayor, the other as observer.

\subsection{Workshops Format}

The workshops were organised into four main parts.

Part I: Introduction. This is the ice-breaker part. Its purpose is to help the Designers and Mayor of the game know each other, besides introduce the players to the the design of interactive solutions. Before starting the game play, children are asked whether they use technological devices in their everyday life and their experience with co-creating smart interactive objects. The Mayor briefly explains the goal of the workshop and what smart interactive objects, inputs and outputs are. For instance, a smart interactive object is introduced as follows: an object that can sense its environment (has sensing capabilities) or can be triggered by a person and subsequently has some sort of reaction.

Part II: Scaffolding. This is the warm-up part and its purpose is to familiarise players with the tools and the concept of the game. The Input and Output Cards and the Scaffolding Map (see Fig. 1) are presented and explained. As a first step, players are asked successively to choose a random card and try to think of what it represents. In case of difficulty in understanding, the Mayor suggests players to read also the description under the title. As a second step, players are asked to take randomly one Input and one Output Card, choose an Environment Card to place on the Scaffolding Map and think of an interaction scenario with them.

Part III: Board game. The rules of the game are explained to the children and they are given the necessary materials to start. At the end of the game-play, players share their ideas with the moderator, according to the rules. They can also be asked to write down their ideas.

Part IV: Questionnaires and interviews. As a last part, self-report questionnaires are given to children to fill in. Their impressions are also orally elicited.

\subsection{Data Collection}

Photos and videos. Data related to the ideas generated by children with the game were collected via photos and video-recordings. 
Questionnaires. Data concerning participants' engagement were collected via a self-report questionnaire with two instruments from the standardised Fun Toolkit for children [29]: the Smiley-o-meter and the Again-and-Again table. The questionnaire asked children: how much they liked playing with SNaP using the Smiley-o-meter 5-point Likert scale, ranging from "not at all" (1) to "very much" (5); whether they "would do it again", using the Again-and-Again-Likert scale with answers "definitely yes", "maybe", "absolutely no".

For quantitatively assessing children's overall experience with the game, beyond engagement, participants were asked to fill the Expectation Rating (ER) questionnaire. This asked two questions in relation to children's expectations before playing the game, and children's experience after playing it [32]. It is a questionnaire rapid to fill in and hence it could be administered to participating children before and after the game-play. Questions were of the following form:

- Before playing (expectation rating): "How difficult or easy do you expect this task to be?"

- After playing (experience rating): "How difficult or easy did you find this task to be?"

Tasks were as follows: learning the game rules; ideating smart interactive objects with the game. Answers were given on a 7-point Likert scale, ranging from "very difficult" (1) to "very easy" (7). The questionnaire also probed children concerning ideas for improving the game, with an open-ended question.

Observations and interviews. Data related to children's experience of the game were also collected and integrated with observations and interviews. Observations were both direct and indirect in the form of videos. Direct observations were by two HCI experts: one acting as Mayor during the game play, and the other as observer. The HCI experts collected their observations independently and then compared their notes, resolving doubts through discussion or by referring back to videos. Interviews were unstructured, in the form of questionanswering during the workshops.

\subsection{Results and Reflections for Workshop 1}

Ideas. At the beginning of the game, each player, in agreement with the others, selected a specific mission. As Table 2 shows, the ideas for the selected missions were simple and mostly described the interaction of few Input and Output Cards with Environment Cards. Interestingly, Players 2 and 3 augmented with smart capabilities the MOTION sensor and the CAMERA.

The generated ideas were coherent with the mission selected at the beginning of the game. Also, all the conceived combinations among the different cards were generally feasible. These two aspects can be considered indicators of the quality of the generated ideas through the game-play. 
Table 2. Ideas generated during the workshop with 11-years-old children. Missions the ideas relate to are reported in italics; the employed cards are in capital letters

\begin{tabular}{|l|l|}
\hline Players & Interactive objects \\
\hline 1st & $\begin{array}{l}\text { In order to guide visitors towards hidden areas, STREET SIGNS point to } \\
\text { hidden parts of the parks with LIGHTS. LIGHTS must be switched on } \\
\text { when the DISTANCE input detects that somebody approaches the signs. }\end{array}$ \\
\hline 2nd & $\begin{array}{l}\text { In order to make sure the visitors respect the park during and after the fes- } \\
\text { tival, when a person throws garbage on the ground, a (VIDEO)CAMERA, } \\
\text { which is always switched on, intercepts this situation. Thus, a red light } \\
\text { (LIGHT UP) is switched on and a SOUND alarm is produced. A police- } \\
\text { man, attracted by the alarm, goes there using a BICYCLE, and brings } \\
\text { the person to the closest trash bin. }\end{array}$ \\
\hline 3rd & $\begin{array}{l}\text { In order to make sure the park is accessible to anybody, 1. there are ROCKS } \\
\text { and SWINGS with MOTION sensors and SOUND actuators, to alert blind } \\
\text { people of obstacles; } 2 \text {. there is a BRIDGE with a MOTION sensor and } \\
\text { a DISPLAY; the MOTION sensor detects a person on a wheelchair near } \\
\text { the BRIDGE, thus the DISPLAY alerts other people to pay attention. }\end{array}$ \\
\hline 4th & $\begin{array}{l}\text { In order to add playful and interactive attractions to the park, there are } \\
\text { MOTION and LUMINOSITY sensors on a BRIDGE over WATER, and } \\
\text { LIGHTS to enlighten WATER under the BRIDGE. The MOTION sensor } \\
\text { detects when people pass on the BRIDGE; thus WATER has brilliant } \\
\text { LIGHT COLOURS that depend on the detected LUMINOSITY level. }\end{array}$ \\
\hline
\end{tabular}

Experience. During the game all the players seemed to be very committed in identifying how each gained card could be exploited in combination with the others. This commitment was also confirmed by the adequate role they were able to assign to some jolly cards: all the players received at least one such card, and they exploited them coherently with the mission idea and in a way that enriched and gave value to the card combination already in place. This can be considered an indication of their level of comprehension of the cards (they were able to identify the right additional cards that could be combined with the others), as well as their commitment to generate rich, interesting ideas.

Player 1 and Player 3 experienced some troubles as they did not gain coins during the game path. For this reason, the Mayor decided to modify the game rules on the spot, to provide each player with 2 coins at the start of the game.

Also, nobody wanted to exchange cards with the other players when they reached the related square in the game path, as in fear they might need all their cards later. For tackling this situation, we decided, on the fly, to introduce penalties in case of missing card exchanges. However, generally, players were most willing to collaborate and help each other, without feeling in competition. For instance, when Player 4 was in trouble in generating an idea ("what can I make?"), all the others tried to give advice. This player, who during the game appeared the one with most difficulties in conceiving ideas, in the end was able to present an interesting and coherent idea, also thanks to the received help. 
The data collected prior to the game-play through the ER questionnaire highlighted that players were worried about the complexity of the game: they had expected that learning the game would be complex enough $(\bar{x}=3.25, \min =3$, $\max =4)$ and that creating interactive games would be complex enough $(\bar{x}=$ $3.25, \min =2, \max =4)$. However, after playing the game, they reported a better experience: learning the game had been easy enough or easy $(\bar{x}=5.75$, $\min =5, \max =7)$, and creating interactive games had been easy enough $(\bar{x}=5, \min =4, \max =6)$. Overall, such quantitative results seem to confirm the qualitative results concerning children's positive experience of the game.

Players' suggestions for the game were all related to having a longer gameboard path with the opportunity to gain a greater number of cards, as they felt that the duration of the game-play was too short, e.g., they all loudly complained when the Mayor announced the end of the game-play.

Engagement. The data collected through the engagement survey were very positive: all the players said that they liked playing very much and that they would definitely like to play it again.

\subsection{Results and Reflections for Workshop 2}

Ideas. At the beginning of the game-play, each player, in agreement with the others, chose a specific mission. The conceived ideas are reported in Table 3 . The ideas for the selected missions were less simple than those of younger children, using almost all cards collected during the game-play. Interestingly, some of their ideas seem to indicate the need of services, such as publishing data on a web site, which were not foreseen in the game.

One emerged problem was that participants exploited the elements represented by the Environment Cards just as ingredients of possible scenarios occurring at the park, not properly as objects to be augmented by means of inputs and outputs. This is evident, for example, in the idea generated by the fourth player (see Table 3): paths, benches, bicycles were used only as elements of the narration - no smart interactions were conceived for these objects. This led us to address the need to enforce a stronger scaffolding phase, already identified during one of the pilot workshops, by introducing digital examples that can show more effectively how nature elements can be augmented.

Experience. During the game session it was evident that participants tried hard to exploit as many cards as possible among those collected during the gameplay; something which was not observed with the younger children. Contrary to younger children, the older children seemed to care less about generating ideas. This suggests that the game board for older children should enable for a more complex game-play, consistently with the literature on game design for teens [1].

Also in the case of this workshop, data collected before the game through the ER questionnaire highlighted that participants thought that learning the game would be complex $(\bar{x}=3.5, \min =2, \max =6)$ and to create interactive 
Table 3. Ideas generated during the workshop with 14-years-old children. Missions the ideas relate to are reported in italics; the exploited cards are in capital letters

\begin{tabular}{|l|l|}
\hline Players & Interactive objects \\
\hline 1st & $\begin{array}{l}\text { In order to guide visitors towards hidden areas, a MOTION sen- } \\
\text { sor detects when a BICYCLE passes close to STREET LIGHTS. } \\
\text { The LIGHT-UP actuator then switches on lights. The MOVE } \\
\text { actuator makes lights rotate to indicate the path to an hidden } \\
\text { point that is worth being visited. }\end{array}$ \\
\hline 2nd & $\begin{array}{l}\text { In order to make sure the visitors respect the park during and } \\
\text { after the festival, a TOUCH sensor detects when somebody trows } \\
\text { something into a TRASH CAN, thus the MAKE SOUND and } \\
\text { LIGHT UP actuators create a joyful effect (as a reward). }\end{array}$ \\
\hline 3rd & $\begin{array}{l}\text { In order to make sure the park is accessible to anybody, I would } \\
\text { define a PATH that facilitates walking for disabled people. Along } \\
\text { this PATH, BENCHES are augmented so that if a person feels } \\
\text { sick she or he can sit on it, and the HEART RATE and TEM- } \\
\text { PERATURE sensors measure her or his body parameters. The } \\
\text { person can call for help by pressing the TOUCH button; a LO- } \\
\text { CATION sensor communicates the precise position of the bench. }\end{array}$ \\
\hline 4th & $\begin{array}{l}\text { In order to add playful and interactive attractions to the park, } \\
\text { there is a PATH with BICYCLES and BENCHES that is enlight- } \\
\text { ened (LIGHT UP). Along the path, there is a TREE augmented } \\
\text { with a button (TOUCH). By pressing the button, one can take a } \\
\text { picture (CAMERA) with the beautiful nature landscape in the } \\
\text { background. The picture is shown on a DISPLAY installed on } \\
\text { the tree, and also on the web site of the park. }\end{array}$ \\
\hline
\end{tabular}

games would be also complex $(\bar{x}=3.25, \min =3, \max =4)$. However, after the game experience, they expressed that learning the game had been easy $(\bar{x}=5$, $\min =3, \max =7)$ and that creating interactive games had been easy enough $(\bar{x}=3.5, \min =3, \max =5)$.

Like younger players, also older players suggested to define a longer gameboard path with more opportunities to gain Nature Cards.

Engagement. Like with younger children, also older children seemed to be highly engaged: through the post-game-play engagement questionnaire, also older children reported that they liked playing the game very much and that they would definitely like playing it again.

\section{Conclusions and Future Work}

This paper reports research in the area of meta-design with children, at the intersection of two research lines: children co-designing as protagonists; children co-designing smart nature ecosystems. The paper starts outlining the relevant literature and then moves on to its core matters. It describes the $\mathrm{SNaP}$ board 
game, which fosters children's participation as protagonists in the co-design of smart interactive nature ecosystems for them.

The genesis of the game is described and pilot workshops which led to the version presented in this paper are reported. Then the paper delves into the description of the two latest workshops with the game, one with 11-years old children and the other with 14-years old children. Both workshops enabled researchers to collect rich data, qualitative and quantitative, concerning ideas generated by children through the game-play, their engagement with the game, and their overall experience with the game.

Data were analysed and compared. Results are overall positive, indicating that the game enabled children to generate ideas for smart interactive nature environments. Moreover, all children, independently of their age group and gender, were engaged with the game. Differences were noted in the experience according to age: younger children seemed keen on their own ideas, and reluctant to sacrifice cards they could use for their ideas; older children seemed to be more interested in using as many cards as possible per se, and make their idea "as complex as possible". Such data were reflected over for improving the game.

The contextual nature of the conducted research limits its generality but produced a rich set of suggestions for improving the game and its toolkit. For instance, in line with the obtained results, future editions of the game will enable longer game-play sessions. Further cards, e.g., for web services, will be added to the deck of Nature Cards, in order to enable participants to add further smart behaviours (e.g., posting photos in a web app). The Scaffolding Map will be improved and made interactive, and show video examples to children. The gameboard will be divided into diverse levels, of different complexity, to accommodate the different age or experience of the players in an adaptive fashion, e.g., [9].

Our future work will especially focus on the challenge of supporting the transformation of the ideas generated through the board game into concrete smart objects that can bring children back to the exploration of outdoor environments.

\section{References}

1. Adams, E.: Fundamentals of Game Design. Pearson-Allyn and Bacon (2009)

2. Angelini, L., Mugellini, E., Couture, N., Abou Khaled, O.: Designing the interaction with the internet of tangible things: A card set. In: Proc. of the Twelfth International Conference on Tangible, Embedded, and Embodied Interaction. pp. 299-306. TEI '18, ACM, New York, NY, USA (2018). https://doi.org/10.1145/3173225.3173288

3. Anggarendra, R., Brereton, M.: Engaging Children with Nature Through Environmental HCI. In: Proc. of the 28th Australian Conference on ComputerHuman Interaction. pp. 310-315. OzCHI '16, ACM, New York, NY, USA (2016). https://doi.org/10.1145/3010915.3010981

4. Baykal, G.E., Goksun, T., Yantaç, A.E.: Customizing Developmentally Situated Design (DSD) Cards: Informing Designers About Preschoolers' Spatial Learning. In: Proc. of the 2018 CHI Conference on Human Factors in Computing Systems. pp. 592:1-592:9. CHI '18, ACM, New York, NY, USA (2018). https://doi.org/10.1145/3173574.3174166 
5. Brandt, E.: Designing exploratory design games: A framework for participation in participatory design? In: Proc. of the Ninth Conference on Participatory Design: Expanding Boundaries in Design - Volume 1. pp. 57-66. PDC '06, ACM, New York, NY, USA (2006). https://doi.org/10.1145/1147261.1147271

6. Coyle, K.: Digital technology's role in connecting children and adults to nature and the outdoors (2017), retrieved in September 2018 from https://www.nwf.org/ /media/PDFs/Kids-and-Nature/NWF_ Role-of-Technology-in-Connecting-Kids-to-Nature_\$6-30\$_lsh.ashx

7. Delprino, F., Piva, C., Tommasi, G., Gelsomini, M., Izzo, N., Matera, M.: ABBOT: A Smart Toy Motivating Children to Become Outdoor Explorers. In: Proc. of the 2018 International Conference on Advanced Visual Interfaces. pp. 23:1-23:9. AVI'18, ACM, New York, NY, USA (2018). https://doi.org/10.1145/3206505.3206512

8. Deng, Y., Antle, A.N., Neustaedter, C.: Tango cards: A card-based design tool for informing the design of tangible learning games. In: Proc. of the 2014 Conference on Designing Interactive Systems. pp. 695-704. DIS '14, ACM, New York, NY, USA (2014). https://doi.org/10.1145/2598510.2598601

9. Di Mascio, T., Gennari, R., Melonio, A., Vittorini, P.: The User Classes Building Process in a TEL Project. In: International Workshop on Evidence-Based Technology Enhanced Learning. pp. 107-114. Springer, Berlin, Heidelberg (2012)

10. Dibitonto, M., Tazzi, F., Leszczynska, K., Medaglia, C.M.: The IoT Design Deck: A Tool for the Co-design of Connected Products. In: Ahram, T., Falcão, C. (eds.) Advances in Usability and User Experience. pp. 217-227. Springer International Publishing, Cham (2018)

11. Druin, A.: The role of children in the design of new technology. Behaviour and Information Technology 21, 1-25 (2002)

12. Gennari, R., Matera, M., Melonio, A., Roumelioti, E.: A Board Game and a Workshop for Co-Creating Smart Nature Ecosystems. In: Proc. of the 9th International Conference in Methodologies and Intelligent Systems for Technology Enhanced Learning (mis4TEL 2019). Springer (2019)

13. Gennari, R., Melonio, A., Rizvi, M., Bonani, A.: Design of IoT Tangibles for Primary Schools: A Case Study. In: Proc. of the 12th Biannual Conference on Italian SIGCHI Chapter. pp. 26:1-26:6. CHItaly'17, ACM, New York, NY, USA (2017). https://doi.org/10.1145/3125571.3125591

14. Gennari, R., Melonio, A., Rizvi, M.: The Participatory Design Process of Tangibles for Children's Socio Emotional Learning. In: Proc. of End-User Development. pp. 167-182. IS-EUD 2017, Springer, Cham (2017). https://doi.org/10.1007/9783-319-58735-6_12

15. Gianni, F., Divitini, M.: Designing IoT applications for smart cities: Extending the Tiles Ideation Toolkit. Interaction Design and Architecture(s) pp. 100-116 (12 2017)

16. Gianni, F., Divitini, M.: Designing IoT Applications for Smart Cities: extending the Tiles Ideation Toolkit. IxD\&A 35, 100-116 (2017)

17. Golembewski, M., Selby, M.: Ideation decks: A card-based design ideation tool. In: Proc. of the 8th ACM Conference on Designing Interactive Systems. pp. 89-92. DIS '10, ACM, New York, NY, USA (2010). https://doi.org/10.1145/1858171.1858189

18. Hildén, E., Ojala, J., Väänänen, K.: Development of context cards: A bus-specific ideation tool for co-design workshops. In: Proc. of the 21st International Academic Mindtrek Conference. pp. 137-146. AcademicMindtrek '17, ACM, New York, NY, USA (2017). https://doi.org/10.1145/3131085.3131092 
19. Hourcade, J.P.: Child-Computer Interaction. self (2015)

20. Huyghe, J., Wouters, N., Geerts, D., Vande Moere, A.: Localudo: Card-based workshop for interactive architecture. In: Proc. of the Extended Abstracts of the ACM Conference on Human Factors in Computing Systems 2014 (04 2014). https://doi.org/10.1145/2559206.2581348

21. Iivari, N., Kinnula, M.: Empowering children through design and making: Towards protagonist role adoption. In: Proc. of the 15th Participatory Design Conference: Full Papers-Volume 1. pp. 16:1-16:12. PDC '18, ACM, New York, NY, USA (2018). https://doi.org/10.1145/3210586.3210600

22. Koepfler, J.: Connecting children with nature through smart toy design (2016), Retrieved in September 2018 from https://www.smashingmagazine.com/2016/07/ connecting-children-with-nature-through-smart-toy-design/

23. Kultima, A., Niemelä, J., Paavilainen, J., Saarenpää, H.: Designing game idea generation games. In: Proc. of the 2008 Conference on Future Play: Research, Play, Share. pp. 137-144. Future Play '08, ACM, New York, NY, USA (2008). https://doi.org/10.1145/1496984.1497007

24. Lechelt, Z., Rogers, Y., Marquardt, N., Shum, V.: Democratizing children's engagement with the internet of things through connectus. In: UbiComp 2016 AdjunctProc. of the 2016 ACM International Joint Conference on Pervasive and Ubiquitous Computing (2017). https://doi.org/10.1145/2968219.2971435

25. Lockton, D., Harrison, D., Holley, T., Stanton, N.: Influencing interaction: Development of the design with intent method. vol. 350, p. 5 (01 2009). https://doi.org/10.1145/1541948.1541956

26. Mavroudi, A., Divitini, M., Gianni, F., Mora, S., Kvittem, D.R.: Designing IoT applications in lower secondary schools. In: 2018 IEEE Global Engineering Education Conference (EDUCON). pp. 1120-1126 (April 2018). https://doi.org/10.1109/EDUCON.2018.8363355

27. Mora, S., Gianni, F., Divitini, M.: Tiles: A card-based ideation toolkit for the internet of things. In: Proc. of the 2017 Conference on Designing Interactive Systems. pp. 587-598. DIS '17, ACM, New York, NY, USA (2017). https://doi.org/10.1145/3064663.3064699

28. Raftopoulos, M.: Playful card-based tools for gamification design. In: Proc. of the Annual Meeting of the Australian Special Interest Group for Computer $\mathrm{Hu}-$ man Interaction. pp. 109-113. OzCHI '15, ACM, New York, NY, USA (2015). https://doi.org/10.1145/2838739.2838797

29. Read, J.C., MacFarlane, S.: Using the fun toolkit and other survey methods to gather opinions in child computer interaction. In: Proc. of the 2006 Conference on Interaction Design and Children. pp. 81-88. IDC '06, ACM, New York, NY, USA. https://doi.org/10.1145/1139073.1139096

30. Roy, R., Warren, J.: Card-based tools for creative and systematic design. In: Proc. of the Design Research Society DRS2018 conference (TBC). vol. 3, pp. 1075-1087 (2018), http://oro.open.ac.uk/54650/

31. Salen, K., Zimmerman, E.: Rules of Play: Game Design Fundamentals. The MIT Press (2003)

32. Sauro, J., Lewis, J.: Quantifying the User Experience. Morgan Kaufmann (2012)

33. Vaajakallio, K., Mattelmki, T.: Design games in codesign: as a tool, a mindset and a structure. CoDesign 10(1), 63-77 (2014). https://doi.org/10.1080/15710882.2014.881886 